\title{
Coronary and Systemic Hemodynamic Effects of Intravenous Nisoldipine
}

\author{
ALAN L. SOWARD, FRACP, PIM J. De FEYTER, MD, PAUL G. HUGENHOLTZ, MD, \\ and PATRICK W. SERRUYS, MD
}

\begin{abstract}
Systemic and coronary hemodynamic effects of the new dihydropyridine calcium antagonist nisoldipine were studied over a 30 -minute period in 12 patients with angina pectoris. Previously instituted $\beta$-blocker therapy was continued. Nisoldipine was administered in an intravenous bolus of $6 \mu \mathrm{g} / \mathrm{kg}$ over 3 minutes. Heart rate increased as mean aortic pressure and systemic vascular resistance decreased in all patients. Cardiac output increased significantly, from $5.8 \pm 0.3$ to $7.9 \pm 0.5$ liters $/ \mathrm{min}, 10$ minutes after nisoldipine infusion. These trends were maintained over the 30-minute observation period. Coro-
\end{abstract}

nary sinus blood flow increased from $103 \pm 11$ to $139 \pm 13 \mathrm{ml} / \mathrm{min}$ immedlately after nisoldipine, but had returned to the control level by 30 minutes, as had the reduction in coronary vascular resistance. Myocardial oxygen consumption and heart ratesystolic blood pressure product did not change significantly. Nisoldipine is a potent peripheral and coronary vasodilator free of major myocardial depressant effects after acute intravenous administration. The systemic vasodilatory effects appear to outlast the coronary effects over $\mathbf{3 0}$ minutes.

(Am J Cardiol 1986;58:1199-1203)

N

isoldipine is a calcium channel blocking agent of the dihydropyridine class, similar in chemical structure to nifedipine..$^{1,2}$ Nisoldipine has 4 to 10 times the potency of nifedipine in inhibiting vascular smooth muscle, but is less potent in the inhibition of isolated heart muscle. ${ }^{3}$ Nisoldipine may have a preferential effect on the coronary vasculature in vivo, ${ }^{4}$ a potentially desirable effect for treatment of myocardial ischemia. The acute effects in humans of intravenous nisoldipine on coronary and peripheral vasculature and left ventricular function were recently shown., The increase in heart rate after nisoldipine administration and the lack of observed negative inotropic effects indicate that in clinical usage, nisoldipine may be combined with a $\beta$-adrenergic blocking drug. Therefore, in this study the patients continued to receive any prescribed $\beta$-blocking drug. The aim was to investigate the persistence of hemodynamic changes induced by a bolus of nisoldipine over a 30-minute study period.

From the Cardiac Catheterization Laboratory, Thoraxcenter. Erasmus University, Rotterdam, The Netherlands. Manuscript received July 31,1985 ; revised manuscript received July 21,1986 , accepted July 22, 1986.

Address for reprints: Patrick W. Serruys, MD, Thorax Center. Catheterization Laboratory, P.O. Box 1738, 3000 DR Rotterdam, The Netherlands.

\section{Methods}

Twelve patients ( 10 men, 2 women) undergoing cardiac catheterization for investigation of suspected coronary artery disease were studied. Mean age was 54 years (range 37 to 64) (Table I). All medications except $\beta$-adrenergic blocking drugs were discontinued at least 24 hours before the study. Beta-blocker therapy was continued in the dose prescribed by the referring physician. Cardiac catheterization was performed with the patient fasting and without premedication using a right antecubital approach. A Webster coronary sinus thermodilution catheter was positioned to allow recording of coronary sinus blood flow by the continuous thermodilution technique ${ }^{7}$ and sampling of blood for oxygen saturations. The catheter position was determined by initial contrast injection and subsequent fluoroscopy and was kept stable. A No. 7Fr Swan-Ganz thermodilution catheter was positioned with the tip at the bifurcation of the main pulmonary artery for pressure measurements and determination of cardiac output. A No. $8 \mathrm{Fr}$ Millar pigtail catheter with tip manometer for pressure recording was positioned in the ascending aorta. Blood for aortic oxygen saturation could be taken through this catheter.

Nisoldipine, $6 \mu \mathrm{g} / \mathrm{kg}$, was infused intravenously over 3 minutes, with care taken to minimize exposure to light. Heart rate, coronary sinus blood flow, aortic, 
TABLE I Patient Clinical and Angiographic Data

\begin{tabular}{rrlccccc}
\hline Pt & Age $(\mathrm{yr}) \&$ Sex & Beta Blocker & Dose (mg) & Time (hr) & Prior Infarct & CAD & EF (\%) \\
\hline 1 & $54 \mathrm{M}$ & Metoprolol & $2 \times 50$ & 6 & + & 3 & 0.71 \\
2 & $58 \mathrm{M}$ & $\ldots$ & $\ldots$ & $\ldots$ & + & 1 & 0.46 \\
3 & $50 \mathrm{M}$ & Atenolol & $1 \times 100$ & 4 & - & 3 & 0.62 \\
4 & $50 \mathrm{M}$ & Atenolol & $1 \times 100$ & 2 & - & 1 & 0.74 \\
5 & $42 \mathrm{M}$ & Metoprolol & $2 \times 50$ & 2 & + & 3 & 0.39 \\
6 & $58 \mathrm{M}$ & Metoprolol & $2 \times 25$ & 2 & + & 3 & 0.35 \\
7 & $64 \mathrm{M}$ & Metoprolol & $2 \times 50$ & 3 & + & 3 & 0.71 \\
8 & $56 \mathrm{M}$ & Metoprolol & $2 \times 50$ & 6 & - & 2 & 0.45 \\
9 & $54 \mathrm{~F}$ & Metoprolol & $2 \times 100$ & 6 & - & 0 & 0.59 \\
10 & $64 \mathrm{~F}$ & Atenolol & $3 \times 50$ & 8 & + & 2 & 0.73 \\
11 & $59 \mathrm{M}$ & Propranolol & $4 \times 10$ & 4 & + & 2 & 0.67 \\
12 & $37 \mathrm{M}$ & $\ldots$ & $\ldots$ & $\ldots$ & 3 & 0.65 \\
\hline
\end{tabular}

Time $(\mathrm{hr})=$ time between last intake of $\beta$ blocker and study.

$\mathrm{CAD}=$ coronary artery disease; $\mathrm{EF}=$ left ventricular ejection fraction.

pulmonary and right atrial pressures, aortic and coronary sinus oxygen saturations and cardiac output were measured in the control state before nisoldipine infusion and as close as possible to 10,20 and $30 \mathrm{~min}$ utes after completion of the infusion. Heart rate, oxygen saturations and coronary sinus blood flow were measured again immediately upon cessation of nisoldipine infusion and hemoglobin levels were determined before and after the study. Standard left ventriculography and coronary angiography were then performed. Left ventricular ejection fractions were calculated from the right anterior oblique projection. Aortic and coronary sinus oxygen contents were given by hemoglobin $(\mathrm{g} / 100 \mathrm{ml}) \times$ oxygen saturation $\times 1.36$, myocardial oxygen consumption by coronary blood flow $X$ aortocoronary sinus oxygen difference and peripheral vascular resistance by the ratio of mean aortic - right atrial pressure difference to cardiac output. Coronary vascular resistance was given by the ratio of mean aortic pressure to mean coronary blood flow.

Statistical analysis: Values are mean \pm standard error of the mean, using 2-way analysis of variance (Duncan new multiple-range test) for repeated measurements. When overall significance was found, multiple comparisons were used to delineate which paired comparisons were significantly different at the $\mathbf{0 . 0 5}$ level.

\section{Results}

Ten patients were taking $\beta$-blocking drugs and 11 had significant coronary artery disease, defined as at least $50 \%$ luminal diameter narrowing in a major coronary artery. Mean ejection fraction was 0.59 (range 0.35 to 0.74 ). There was no difference in hemoglobin values measured before and after the study. Patient clinical and angiographic data are summarized in Table I. No patient had angina pectoris or other untoward symptoms during the study.

Heart rate increased and systemic vascular resistance decreased with a decrease in mean aortic pressure in all patients (Fig. 1). Cardiac output had increased from $5.8 \pm 0.3$ to $7.9 \pm 0.5 \mathrm{liters} / \mathrm{min}(36 \pm 4 \%$, $\mathrm{p}<0.05)$ at 10 minutes to $7.2 \pm 0.5$ liters $/ \mathrm{min}(24 \pm 3 \%$, $\mathrm{p}<0.05)$ at 20 minutes and was still significantly ele- vated at $6.8 \pm 0.4$ liters $/ \min (18 \pm 3 \%, \mathrm{p}<0.05)$ at 30 minutes after nisoldipine. Control stroke volume was $91 \pm 5 \mathrm{ml}$ and increased by $17 \pm 3 \%(\mathrm{p}<0.05)$ at 10 minutes, by $7 \pm 2 \%(\mathrm{p}<0.05)$ at 20 minutes and by $6 \pm$ $2 \%(p<0.05)$ at 30 minutes. The indexes of these mea-
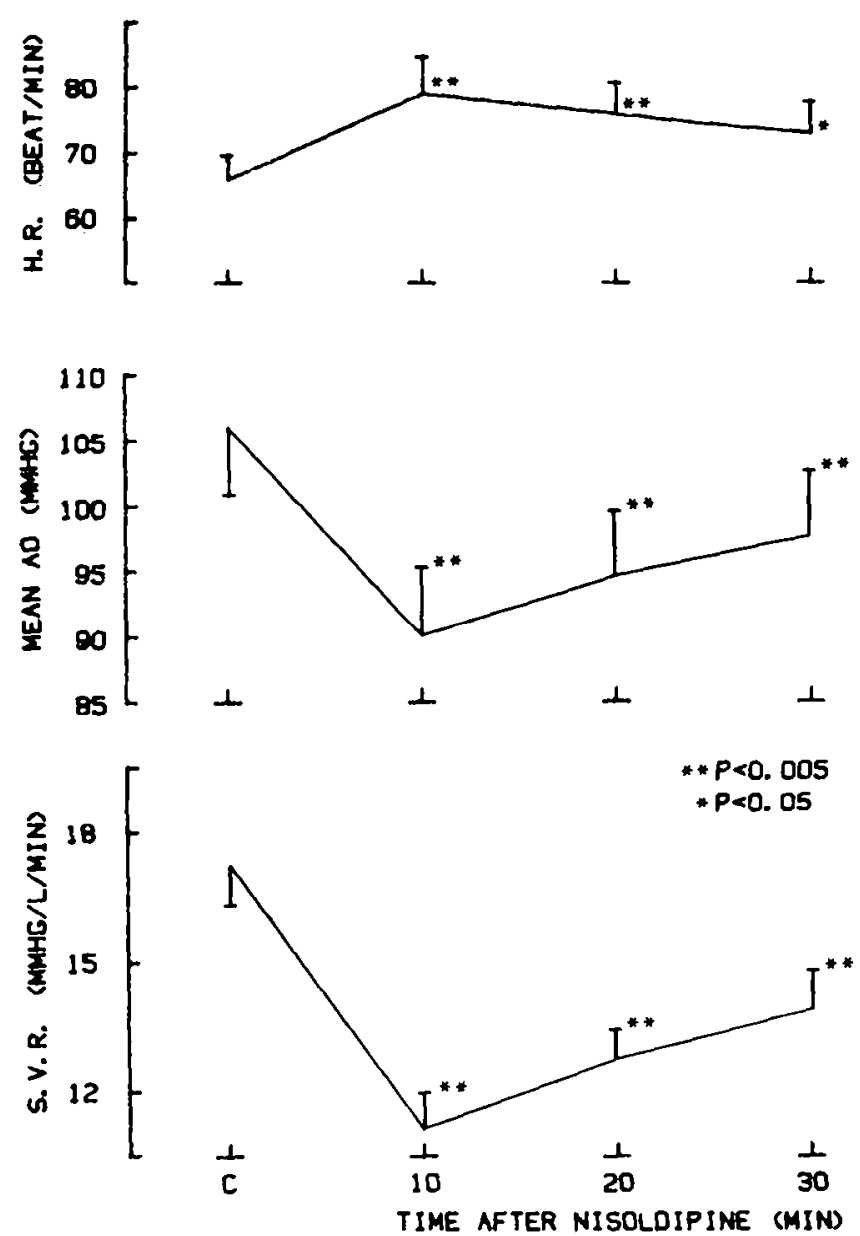

FIGURE 1. Changes in heart rate (H.R.), mean aortic (AO) pressure and systemic vascular resistance (S.V.R.) before (C) and at 10, 20 and $\mathbf{3 0}$ minutes afler nisoldipine. The $p$ values are given with respect to control measurements. 
surements are displayed in Figure 2. An increase in coronary sinus blood flow occurred in all patients, as did a fall in coronary vascular resistance. The lowest percentage increase in coronary sinus blood flow occurred in the 2 patients with the lowest ejection fractions. Mean control flow was $103 \pm 11 \mathrm{ml} / \mathrm{min}$, increasing to $139 \pm 13 \mathrm{ml} / \mathrm{min}(38 \pm 9 \%, \mathrm{p}<0.05)$ immediately after nisoldipine infusion. At 10 minutes the change was $23 \pm 9 \%$ ( $p<0.05)$, at 20 minutes $13 \pm$ $4 \%(\mathrm{p}<0.05)$ and by 30 minutes the mean coronary flow had returned to the control value. Coronary vascular resistance decreased from $1.15 \pm 0.13$ to $0.66 \pm$ $0.08 \mathrm{~mm} \mathrm{Hg} / \mathrm{ml} / \mathrm{min}(40 \pm 4 \%, \mathrm{p}<0.05)$ immediately after nisoldipine. At 10 minutes it had decreased $25 \pm$ $5 \%$ (p <0.05), at 20 minutes $18 \pm 4 \%$ (p 0.01) and at 30 minutes $9 \pm 6 \%$ (difference not significant) (Fig. 3). The increases in myocardial oxygen consumption of $4 \%, 3 \%$ and $2 \%$ at 0,10 and 20 minutes after nisoldipine infusion were not significant, nor was the $10 \%$ decrease $(p=0.8)$ at 30 minutes. Systolic aortic pressure-heart rate product was unchanged. Correcting myocardial oxygen consumption for heart rate produced a decrease of $18 \%(p<0.05)$ immediately after, $20 \%(p<0.05)$ at 10 minutes, $11 \%(p<0.05)$ at 20 minutes and $12 \%$ (difference not significant) at 30 minutes after nisoldipine. Thus, at least to 20 minutes after nisoldipine, perfusion remains in excess of demand.

Mean pulmonary arterial pressure was slightly increased at 10 minutes after nisoldipine, from $18 \pm 2$ to $20 \pm 2 \mathrm{~mm} \mathrm{Hg}(17 \pm 6 \%, \mathrm{p}<0.05)$ but had returned to the control value at 20 minutes. Similar changes occurred in mean right atrial pressures.

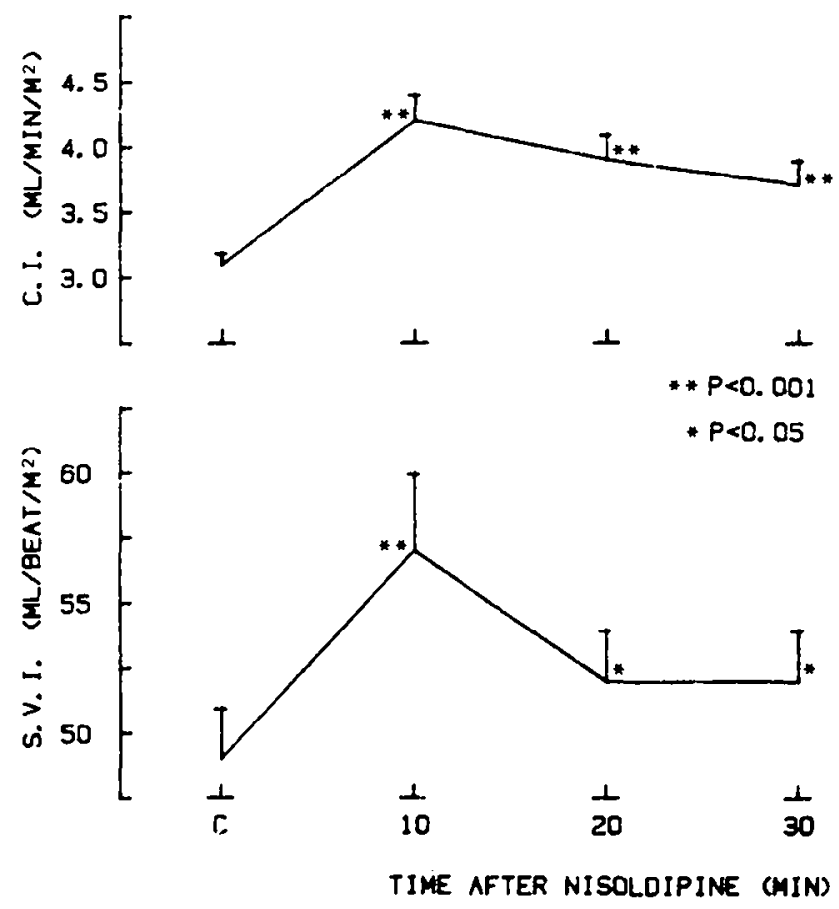

FIGURE 2. Mean cardlac index (C.I.) and stroke volume index (S.V.I.) before (C) and 10, 20 and 30 minutes after nisoldipine. The $p$ values are given with respect to control measurements.

\section{Discussion}

This study confirms the persistence of some hemodynamic effects over 30 minutes after an intravenous bolus of nisoldipine. Heart rate, stroke volume and cardiac output remained elevated at 30 minutes, aortic pressures and systemic vascular resistance were decreased. In this regard nisoldipine mimics the effects of nifedipine with afterload reduction inducing reflex sympathetic activation. ${ }^{8}$

Since approximately $85 \%$ of coronary sinus blood flow arises from the left ventricle, ${ }^{9}$ measurements reflect left ventricular coronary flow. Research data support a very close link between myocardial oxygen demand and coronary blood flow, with the changing oxygen requirements producing alterations in coronary vascular resistance and flow on a beat-to-beat basis. ${ }^{10}$ Thus, the increase in flow observed after nisoldipine in the face of an unchanged myocardial oxygen consumption reflects a perfusion of the left ventricle in excess of demand, one means by which calcium antagonists may be beneficial in the treatment of ischemia. To be beneficial, such increased supply should be distributed to ischemic or potentially ischemic myocardium as well as to normal area. In dogs with acutely

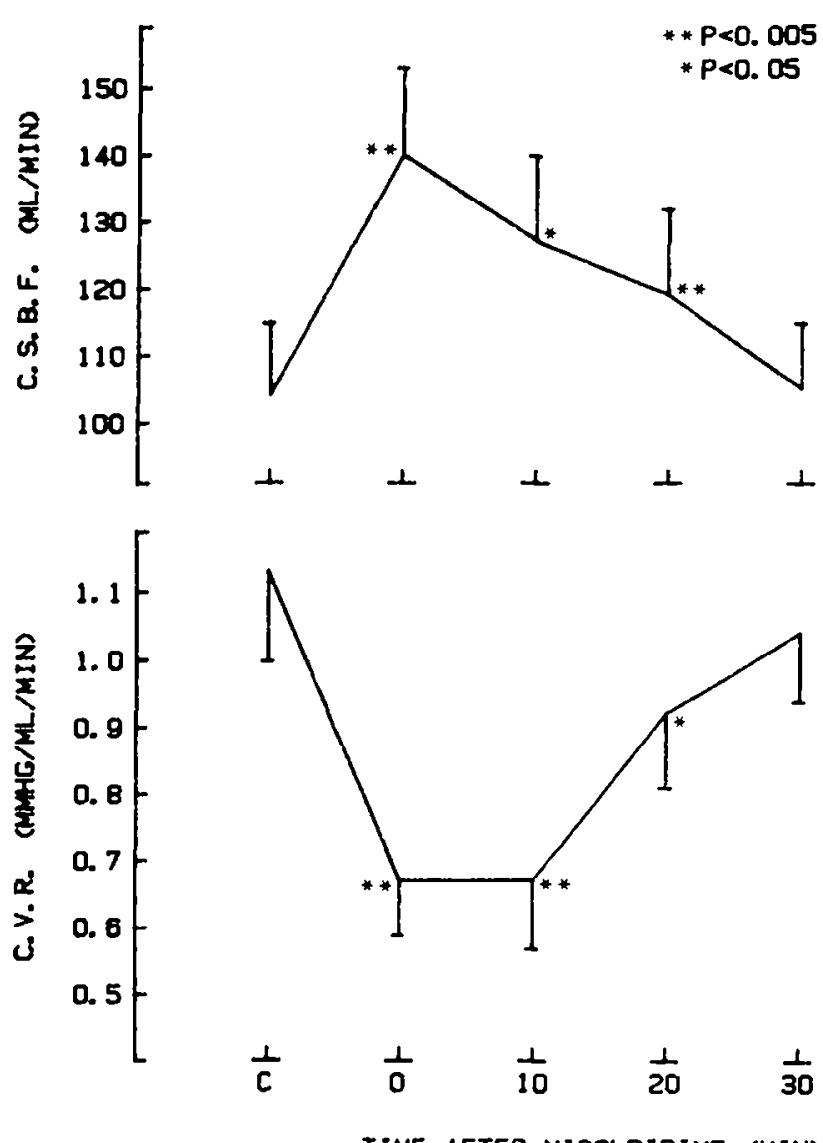

TIME AFTER NISOLDIPINE (MIN)

FIGURE 3. Mean coronary sinus blood flow (C.S.B.F.) and coronary vascular resistance (C.V.R.) belore (C), immediately after, and 10 , 20 and $\mathbf{3 0}$ minutes afier nisoldipine. The $p$ values are given with respect to control measurements. 
occluded left anterior descending arteries, nisoldipine increases coronary collateral flow to the ischemic zone, with equal distribution to the subendocardium and subepicardium. ${ }^{11} \mathrm{~A}$ study of 10 patients with coronary artery disease, using a $\mathrm{C}^{-14}$ lactate infusion and coronary sinus lactate estimations, suggested that nisoldipine reduced lactate production by chronically underperfused myocardium. ${ }^{12}$ While increased oxygen supply was considered to play a part, dipyridamole, a powerful coronary dilator, has few antianginal properties and does not improve myocardial lactate metabolism, indicating that other actions of nisoldipine may be operative in myocardial ischemia. Reduction of left ventricular prcload is considercd an important component of the antianginal action of nitrates. While nifedipine has little such tendency, ${ }^{13}$ nisoldipine was shown to reduce markedly left ventricular end-diastolic pressure in fluid-loaded pigs without depression of myocardial contractility. ${ }^{14}$ It was suggested that antianginal effects of nisoldipine may include corrcction of impaired ventricular relaxation with reduction in diastolic wall stress.

At 10,20 and 30 minutes, a greater degree of reduction in vascular resistance was present in the systemic than in the coronary system (Fig. 4). In an earlier study coronary vascular resistance was reduced by $50 \%$ immediately after nisoldipine, while systemic vascular resistance was reduced by $30 \%$, suggesting relative selectivity for the coronary vasculature. ${ }^{5}$ Such selectivity could result from an increased number of nisoldipine receptor sites or receptors of greater sensitivity in the coronary vascular wall. The duration and degree of systemic effects of nisoldipine in the current study may be due to the fact that coronary vascular autoregulation became operative within the 30 -minute observation period. Although the mediators of this control that couples vascular resistance to myocardial metabolism are unknown, adenosine and other nucleotides, prostaglandins, carbon dioxide and hydrogen ions have been proposed as possibilities. Although autoregulation is not unique to the coronary circulation and also occurs in peripheral vascular beds, coronary autoregulatory mechanisms may be more potent in effecting a return of the nisoldipine-induced changes toward control. Other explanations for the observed changes include peripheral vascular selectivity for nisoldipine rather than coronary selectivity ${ }^{3}$ or disparate effects on the coronary vasculature of vasoconstrictors such as noradrenaline released by reflex sympathetic mechanisms.

Beta-blocking drugs used alone produce reductions in myocardial oxygen consumption, increase coronary vascular resistance ${ }^{15,16}$ and reduce blood flow, ${ }^{17}$ changes that may increase sensitivity to the vasodilator effects of nisoldipine. The lack of control data before $\beta$-blocker therapy makes it difficult to speculate on the additive effects in the 10 patients taking these medications. Certainly the increase in heart rate was similar to that observed in the previous study, in which $\beta$ blocker therapy was discontinued. ${ }^{5,6}$ Some patients were, however, using $\beta$-blocker dosages lower than those generally recommended, and the rest heart rate in a few suggests suboptimal $\beta$ blockade. Studies with nifedipine and $\beta$-blocking drugs show attenuation of the reflex positive inotropic and chronotropic changes. ${ }^{17,18}$ As the increase in heart rate after nisoldipine tended to offset any reduction in cardiac work, the combination with $\beta$ blockade may be beneficial.

The increase in right heart pressures probably reflects the increase in venous return. The absence of venodilatory effects has been shown for nifedipine ${ }^{19}$ but has not been investigated in humans for nisoldipine.

In a recent study on open-chested anesthetized dogs, nisoldipine reduced myocardial infarct size after coronary occlusion by $31.4 \% .20$ This was considered to be in part a result of afterload reduction with reduced left ventricular wall stress, as it was pointed out that other agents producing afterload reduction such as nitroprusside have been ineffective in preventing ischemic myocardial damage. ${ }^{21,22}$ Other animal experiments with nisoldipine show it to be useful in preventing ventricular arrhythmias resulting from acute myocardial ischemia in rats ${ }^{23}$ and effective in preventing ATP breakdown in the ischemic rat heart. ${ }^{24}$ In the latter study, ischemia was induced by lowering aortic perfusion and nisoldipine was given through the aorta. Nisoldipine was found to induce coronary vasodilatation at very low doses and a significant negative inotropic effect only became apparent at concentrations 30

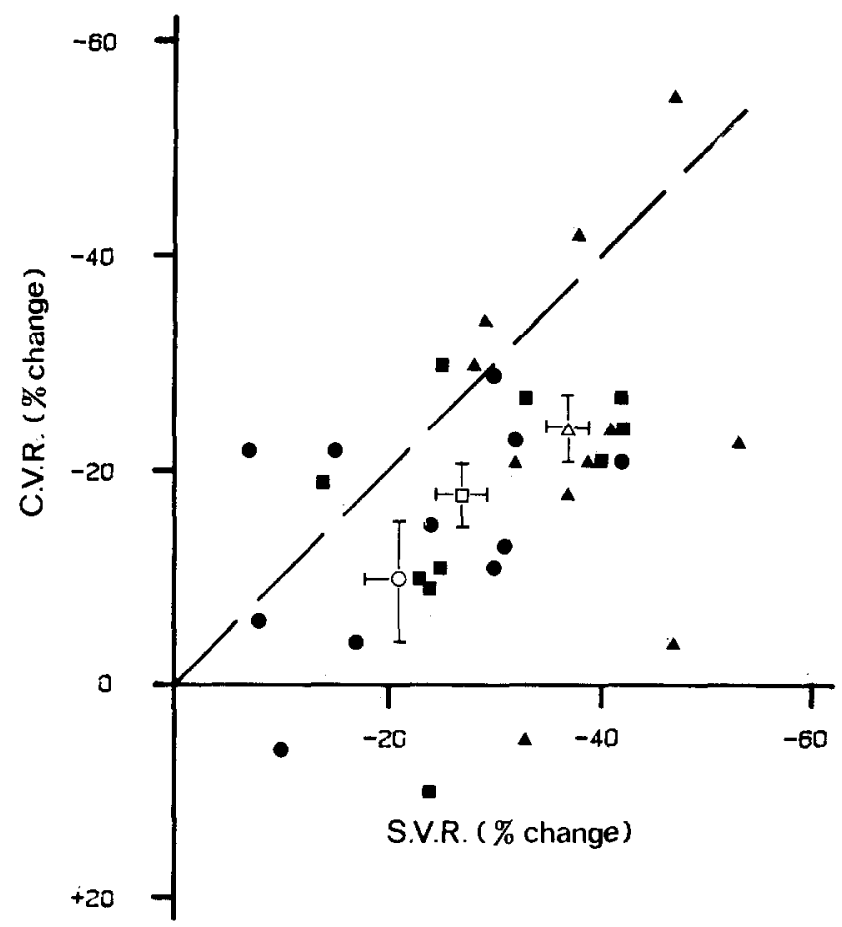

FIGURE 4, Individual percent changes in systemic vascular resistance (S.V.R.) and coronary vascular resistance (C.V.R.) at 10 minutes (triangles, $\mathrm{n}=11$ ), 20 (squares, $\mathrm{n}=11$ ) and 30 minutes (dots, $\mathbf{n}=10$ ) after nisoldipine. Mean changes ( \pm standard error) are shown by the hollow symbols. Broken line indicates the line of identity. 
times higher. Purine efflux from the ischemic hearts was suppressed in a dose-dependent fashion, suggesting preservation of myocardial ATP. A direct effect on myocardial enzyme levels was postulated. With the afterload-reducing properties of nisoldipine, the lack of significant negative inotropic effects from doses producing the vascular changes and the possibility of reducing infarct size, the drug may have clinical usefulness for treatment of acute myocardial infarction complicated by increased systemic blood pressure.

Acknowledgment: We thank the nursing and technical staff of the cardiac catheterization laboratory for their valued and skilled assistance in the performance of this study and Gusta Koster and Anja van Huuksloot for their tireless and careful preparation of the manuscript.

\section{References}

1. Takenada T, Usuda S, Nomura T, Maeno H, Sado T. Vasodilator profile of a new 1.4-dihydropyridine derivative, 2.6-dimethyl-4-(3-nitrophenyl-1)4-dihydropy ridine-3.5-dicarboxylic acid 3.2-[N-benzyl- $N$-methylamino) ethyl ester 5-methyl ester hydrochloride (YC-93) Arzneimittelforsch (Drug Res) 1976; 26:2172-2178.

2. Vater W, Kroneberg G, Hoffmeister F, Kaller H, Meng K, Oberdorf A, Puls W, Schlossmann K, Stoepel K. Zur Pharmakologie von 4-(2-'-Nitrophenyl)-2.6 dimethyl-1.4-dihydropyridin-3.5-dicarbon-söuredimethylester (Nifedipine) BAY A 1040. Arzneimittelforsch (Drug Res) 1972;22:1-14.

3. Kazda S, Garthoff B, Meyer H, Schlossmann K, Stoepel K, Towart R, Vater W, Wehinger E. Pharmacology of a new calcium antagonistic compound, isobutyl methyl 1.4-dihydro-2.6-dimethyl 4-(2-nitrophenyl)-3.5-pyridinecarboxylate (nisoldipine, BAY K 5552). Arzneimittelforsch (Drug Res) 1980;30(II) 12:2144-2162.

4. Lathrop DA, Valle-Aguilera JR, Millard RW, Guam WE, Hannon DW, Francis PD, Nakaya H, Schwartz A. Comparative electrophysiologic and coronary hemodynamic effects of diltiazem, nisoldipine and verapamil on myocardial tissue. Am J Cardiol 1982;49;813-620.

5. Serruys PW, Suryapranata H, Planellas ], Wijns W, Vanhaleweyk GLJ, Soward AL, Jaski BE, Hugenholtz PG. Acute effects of intravenous nisoldipine on left ventricular function and coronary hemodynamics. Am J Cardiol 1985;56:140-146.

6. Suryapranata H, Serruys PW, Soward AL, Planellas J, Vanhaleweyk GLJ, Hugenholtz PG. Acute coronary hemodynamic effects of equihypotensive doses of nisoldipine and diltiazem. Aust NZ / Med; 1985;15:685-690.
7. Ganz W, Tamura K, Marcus HS, Donoso R, Yoshida S, Swan H]C. Measurements of coronary sinus blood flow by continuous thermodilution in man. Circulation 1971;44:181-195.

8. Maxwell GM, Rencis V. The effects of a new coronary vasodilator (BAY-A 1040 , nifedipine) on the coronary and systemic hemodynamics in the anaesthetized dog. Aust I Exp Biol Med Sci 1973;51:117-120.

9. Hood WB Jr. Regional venous drainage of the human heart. Br Heart I 1968;30:105-109.

10. Schwartz $G G_{\text {, }} \mathrm{McHale} \mathrm{PA}$. Coronary vasodilation after a single ventricular extra-activation in the conscious dog. Circ Res 1982;50:38-46.

11. Waltier DC, Meils CM, Gross GJ, Brooks HL. Blood flow in normal and acutely ischemic myocardium after verapamil, diltiazem, and nisoldipine [BAY K 5552], a new dihydropyridine calcium antagonist. I Pharm Exp Ther 1981;218:296-302.

12. Rousseau MF, Vincent MF, Hoof F, van den Berghe G, Charlier AA, Pouleur H. Effects of nicurdipine and nisuldipine un myocardial inetabolism, coronary blood flow and oxygen supply in angina pectoris. Am I Cardiol 1984;54:1189-1194.

13. Hugenholtz PG, Michels HR, Scrruys PW, Brower RW. Nifedipine in the treatment of unstable angina, coronary spasm and myocardial ischemia. Am J Cardiol 1981;47:163-173.

14. Verdouw PD, Slager CJ, van Bremen RH, Verkeste CM. Is nisoldipine capable of reducing left ventricular preload? Eur I Pharmacol 1984;98:137140.

15. Schang SJ, Pepine CJ. Effects of propranolol on coronary hemodynamic and metabolic responses to tachycardia stress in patients with and without coronary disease. Cathet Cardiovasc Diagn 1977;3:47-67.

16. Schang S], Pepine CI. Coronary and myocardial metabolic effects of combined glyceryl-trinitrate and propranolol administration. $\mathrm{Br}$ Heart $\mathrm{Y}$ 1978;40:1221-1228.

17. Schanzenbächer P, Gottfert G, Liebau G, Kochsiek K. Coronary hemodynamic and metabolic cffccts of nifedipinc in patients treated with beta-blocking drugs. Am J Cardiol 1985;55:33-36.

18. Wolffenbuttel BHR, Verdouw PD. Nifedipine and myocardial pérformance in the presence and absence of beta-blockade with propranolol. Arch Int Pharmacodyn Ther 1983;266:83-92.

19. Mostbeck A, Partsch L, Peschl L. Investigations on peripheral blood distribution. In: Jatene AD, Lichtlen PR, eds. Proceedings of the 3rd International Adalat Symposium. Tokyo: University of Tokyo Press 1976:91-97.

20. Tumas J, Deth R, Kloner RA. Effects of nisoldipine, a new calcium antagonist, on myocardial infarct size and cardiac dynamics following acute myocardial infarction. I Cardiovasc Pharm 1985;7:361-367.

21. Chiariello M, Gold HR, Leinbach RC, Davis MA, Maroko PR. Comparison between the effects of nitroprusside and nitroglycerin on ischemic injury during acute myocardial infarction. Circulution 1976;54:766-773.

22. Kloner RA, Braunwald E. Review: observations on experimental myocardial ischemia. Cardiovasc Res 1980;14:371-395.

23. Fagbemi O, Parratt JR. Suppression by orally-administered nifedipine, nisoldipine, and niludipine of early, life-threatening ventricular arrhythmias resulting from acute myocardial ischemia. Br I Pharmacol 1981;74:12-14. 24. de Jong JW, Huizer T, Tijssen JGP. Energy conservation by nisoldipine in ischemic heart. Br I Pharmacol 1984;83:943-949. 